S. Fennell · N. Bohorova - M. van Ginkel

J. Crossa $\cdot$ D. Hoisington

\title{
Plant regeneration from immature embryos of 48 elite CIMMYT bread wheats
}

Recelved: 10 March 1995 / Accepted: 7 July 1995

\begin{abstract}
Forty-eight bread wheat (Triticum aestivum L.) released cultivars and elite advanced lines were evaluated for their ability to produce embryogenic callus using three different media. Basal N6 medium supplemented with dicamba (E1), MS medium containing 2,4-D (E3) or MS medium containing 2,4-D plus different amino acids (E5) were used for callus initiation and maintenance. Plant regeneration was achieved on basal MS medium with indole-3-acetic acid (IAA) and 6benzylamino purine (BAP) and rooting on MS with 1naphthaleneacetic acid (NAA). Percentage regeneration varied widely with both genotype and initiation medium, with values ranging from $2 \%$ to $94 \%$. The number of plantlets produced per embryo ranged from 6 to 42 . Thirteen genotypes showed at least 50\% regeneration after culture on E5 medium; 3 genotypes after culture on E3 initiation medium and 1 after initiation on E1. After four subcultures, over a 16-week period, 41 genotypes $(85 \%)$ lost their ability to regenerate plants while the remaining 7 lines $(15 \%)$ retained plant regeneration potential but at reduced levels. E3 medium was found to be the best for maintaining regeneration potential after four subcultures.
\end{abstract}

Key words Bread wheat - Triticum aestivum . Culture medium - Embryogenic callus - Plant regeneration

\section{Introduction}

The genetic modification of plants in vitro via transformation techniques is largely dependent on the ability of the tissue to regenerate whole plants. Wheat imma-

Communicated by Y. Gleba

S. Fennell · N. Bohorova (困) · M. van Gınkel · J. Crossa • D. Hoisington

CIMMYT, International Maize and Wheat Improvement Centre, Lisboa 27, Apdo. Postal 6-641, 06600, Mexico D.F., Mexico ture embryos are the most efficient tissue sources for regenerating whole plants in large numbers (Shimada 1978; Shimada and Yamada 1979; Gosh-Wakerle et al. 1979; Sears and Deckard 1982; Ozias-Akins and Vasil 1982, 1983). Callus induction, maintenance and regeneration from immature embryos have been shown to be genotype-dependent (Sears and Deckard 1982; Maddock et al. 1983; Lazar et al. 1983; Mathias and Simpson 1986) and in addition are strongly influenced by the components of the media used (Elena and Ginzo 1988; Hunsinger and Schauz 1987; He et al. 1989; Ozias-Akins and Vasil 1982; Carman et al. 1988). Mathias and Simpson (1986) assessed the relative contributions made by media additives and genotype in vitro and suggested that the genotype may be more significant than the medium in affecting behaviour in tissue culture.

When the success of conventional breeding techniques is combined with the potential offered by genetic transformation, it is possible that significant contributions can be made to CIMMYT bread wheat germplasm already widely grown in developing countries. The first steps towards the production of stable transgenic plants are the isolation of target genotypes and development of an efficient regeneration system for the host tissue that is to be transformed. For this reason a large number of elite bread wheats were screened for their potential to regenerate plants from immature embryos. From our study of 48 genotypes, optimal genotypes and media were selected that will be used for the initiation of transformation experiments.

\section{Materials and methods}

Forty-eight purified CIMMYT bread wheat cultivars and advanced lines were evaluated for their in vitro culture response (Table 1). The genotypes were purified by controlled selfing for two generations with selections made for uniform progeny. Plants were grown under screen-house conditions at CIMMYT's El Batan experimental stationin the central highlands of Mexico $\left(19^{\circ} 31^{\prime} \mathrm{N}, 98^{\circ} 50^{\prime} \mathrm{W}, 2249\right.$ masl $)$ in 1994. Immature embryos were excised from seeds harvested 13-17 days after anthesis. 
Table 1 Callus formation and percentage regeneration for 48 elite bread wheats on MSR medium using three callus initiation media

\begin{tabular}{|c|c|c|c|c|c|c|c|}
\hline \multirow{2}{*}{ Elite genotype } & \multicolumn{2}{|l|}{ Medium E1 } & \multicolumn{2}{|l|}{ Medium E3 } & \multicolumn{2}{|l|}{ Medium E5 } & \multirow{2}{*}{$\begin{array}{l}\text { Mean plant } \\
\text { regeneration }(\%)^{\mathrm{a}}\end{array}$} \\
\hline & $\begin{array}{l}\text { Callus } \\
\text { formation(\%) }\end{array}$ & $\begin{array}{l}\text { Plant } \\
\text { regeneration(\%) }\end{array}$ & $\begin{array}{l}\text { Callus } \\
\text { formation(\%) }\end{array}$ & $\begin{array}{l}\text { Plant } \\
\text { regeneration(\%) }\end{array}$ & $\begin{array}{l}\text { Callus } \\
\text { formation( } \%)\end{array}$ & $\begin{array}{l}\text { Plant } \\
\text { regeneration(\%) }\end{array}$ & \\
\hline Luan $(X 2)^{b}$ & 100 & 46 & 98 & 63 & 100 & 94 & 67.7 \\
\hline Turaco(X) & 100 & 49 & 100 & 28 & 100 & 88 & 55.0 \\
\hline Mulan(X2) & 100 & 30 & 96 & 33 & 100 & 93 & 52.0 \\
\hline Attula (X1) & 100 & 26 & 100 & 58 & 98 & 69 & 51.0 \\
\hline Angostura (X3) & 84 & 77 & 91 & 21 & 81 & 49 & 49.0 \\
\hline Pavon (X1) & 100 & 45 & 98 & 30 & 88 & 57 & 44.0 \\
\hline Tia.2 (X) & 98 & 45 & 100 & 16 & 98 & 62 & 41.0 \\
\hline Kauz (X3) & 88 & 48 & 81 & 5 & 88 & 68 & 40.3 \\
\hline Munia (X1) & 67 & 33 & 78 & 43 & 63 & 27 & 34.3 \\
\hline Tinamou $(\mathrm{X})$ & 81 & 11 & 93 & 4 & 100 & 86 & 33.7 \\
\hline Junco (x1) & 100 & 22 & 96 & 38 & 100 & 36 & 32.0 \\
\hline Pastor (X) & 80 & 2 & 90 & 22 & 94 & 71 & 31.7 \\
\hline Munia (X2) & 100 & 9 & 100 & 65 & 96 & 20 & 31.3 \\
\hline Don Ernesto (X2) & 94 & 4 & 100 & 12 & 95 & 77 & 31.0 \\
\hline Cettia (X2) & 30 & 15 & 82 & 2 & 30 & 71 & 29.3 \\
\hline Kauz (X2) & 87 & 17 & 85 & 35 & 100 & 27 & 26.3 \\
\hline Sitia (X2) & 100 & 16 & 95 & 6 & 100 & 43 & 21.7 \\
\hline Bobwhite (X1) & 100 & 0 & 96 & 14 & 100 & 50 & 21.3 \\
\hline Tia.3 (X) & 100 & 7 & 100 & 38 & 93 & 18 & 21.0 \\
\hline Catbird (X1) & 100 & 5 & - & - & 73 & 57 & 20.7 \\
\hline Weaver $(\mathrm{X})$ & 57 & 13 & 97 & 2 & 100 & 44 & 19.7 \\
\hline Seri M 82 (X2) & 100 & 10 & 100 & 2 & 100 & 46 & 19.3 \\
\hline - Dharwar Dry (X) & 100 & 13 & 100 & 36 & 98 & 4 & 17.7 \\
\hline Ciano $79(X)$ & 95 & 2 & 97 & 3 & 95 & 40 & 15.0 \\
\hline HD2281 (X) & - & - & 88 & 15 & - & - & 15.0 \\
\hline Loxia $(X)$ & 71 & 6 & 88 & 24 & 80 & 14 & 14.7 \\
\hline Filn $(X)$ & 82 & 7 & 79 & 19 & 95 & 17 & 14.3 \\
\hline SW87.2347 (X) & 30 & 0 & 32 & 33 & 33 & 6 & 13.0 \\
\hline Catbird (X) & 96 & 0 & 92 & 4 & 86 & 32 & 12.0 \\
\hline SW89.1862 (X) & 91 & 0 & 96 & 22 & 85 & 9 & 10.3 \\
\hline Chuan Ma121 (X) & 54 & 7 & 90 & 11 & 65 & 8 & 8.7 \\
\hline Sitella (X2) & 94 & 0 & 100 & 6 & 96 & 19 & 8.3 \\
\hline Irena $(\mathrm{X} 2)$ & 74 & 0 & 2 & 0 & 89 & 24 & 8.0 \\
\hline Sibia $(X)$ & 100 & 6 & 92 & 7 & - & - & 6.5 \\
\hline Baviacora $(\mathrm{X})$ & 100 & 4 & 100 & 2 & 100 & 13 & 6.3 \\
\hline NL 623 (X) & 89 & 4 & 61 & 0 & 83 & 15 & 6.3 \\
\hline Shanghai 4 (X) & 100 & 2 & 98 & 2 & 100 & 15 & 6.3 \\
\hline Opata M $85(\mathrm{X})$ & 70 & 0 & 66 & 9 & 67 & 0 & 3.0 \\
\hline Star (X2) & 86 & 0 & 93 & 0 & 93 & 9 & 3.0 \\
\hline Nanjing $7840(X)$ & 85 & 0 & 100 & 8 & 92 & 0 & 2.7 \\
\hline PRLII/CM 65531 (X) & 100 & 0 & 90 & 0 & 100 & 8 & 2.7 \\
\hline Picus (X) & 73 & 0 & 45 & 0 & 65 & 5 & 1.7 \\
\hline Nesser (X1) & 55 & 0 & 22 & 0 & 73 & 2 & 0.7 \\
\hline Gamtoos (RWA) & 0 & 0 & 0 & 0 & 0 & 0 & 0.0 \\
\hline Redwing (X) & 27 & 0 & 42 & 0 & 31 & 0 & 0.0 \\
\hline Ducula (X2) & 44 & 0 & 34 & 0 & 39 & 0 & 0.0 \\
\hline Nestor (X) & 2 & 0 & 4 & 0 & 0 & 0 & 0.0 \\
\hline Bow*2/PRL (X) & 0 & 0 & 8 & 0 & 5 & 0 & 0.0 \\
\hline
\end{tabular}

${ }^{a}$ Minimum significant difference given by Waller-Duncan $\mathrm{K}$-ratio $t$-test $=30.0$; least significant difference at the 0.05 probability level $=27.2$

Seeds were surface-sterilized first in $70 \%$ ethanol for $1 \mathrm{~min}$, then in $20 \%$ Chlorox containing 10 drops of Tween-80/1 for $20 \mathrm{~min}$ and rinsed three times with sterile de-ionized water. Immature embryos $1-1.5 \mathrm{~mm}$ in size were asceptically excised from the seeds and placed with the scutellum down on the initiation medium. Six embryos were placed in each disposable plastic petri-dish $(60 \times 15 \mathrm{~mm})$ and approximately 50 embryos were plated per treatment with three media being used for each genotype. As there were not always sufficient embryos available for callus initiation on all three media, data from 47 genotypes are available for media E1 and E3 and from 46 genotpes for medium E5.
${ }^{b} \mathrm{X}$ indicates that the genotype was purified by two seasons of controlled selfing of "bagged" spikes. The number indicates a particular plant, if more than one was initially purified

The media used were based on N6 (Chu et al. 1975) and MS media (Murashige and Skoog 1962) with modifications as described by Bohorova et al. (1995). The $\mathrm{pH}$ of all the media was adjusted to 5.7 with $\mathrm{NaOH}$, and $0.8 \%$ agar (Bacto) was added before sterilization. The cultures were incubated in the dark at $26^{\circ} \mathrm{C}$. After 3 weeks on initiation medium (E1, E3 or E5) each piece of callus was cut in two; one-half being placed on regeneration medium and the other half placed on the maintenance medium (the same as that used for callus initiation). Callus cultures were subcultured to fresh media every 3-4 weeks.

Plantlets were regenerated by transferring calli to basal MS medium supplemented with $0.5 \mathrm{mg} / 1$ indole-3-acetic acid (IAA), 
$1 \mathrm{mg} / 1$ 6-benzylamino purine (BAP), $40 \mathrm{mg} / 1$ thiamine, $150 \mathrm{mg} / \mathrm{l}$ L-asparagine and $2 \%$ sucrose (MSR medium). When the plantlets had 4-6 leaves they were transferred to a rooting medium comprised of half-strength MS medium supplemented with $1 \mathrm{mg} / \mathrm{l}$ l-naphthaleneacetic acid (NAA) and $2 \%$ sucrose (MSE medium). The $\mathrm{pH}$ of the medium was adjusted to 57 with $\mathrm{NaOH}$ before sterilization and the addition of $08 \%$ agar (Bacto). Call were incubated in a culture growth room at $26^{\circ} \mathrm{C}$ using a 16 -h light dark photoperiod The plantlets with good root formation were transferred to Jiffy pots and kept in a growth chamber for a week before being transplanted to larger pots and grown to maturity in the greenhouse.

The percentage callus formation was defined as the number of the embryos forming callus divided by the total number of embryos plated on the media Percentage plant regeneration was calculated as the number of call producing at least 6 plantlets, divided by the total number of calli produced. One or 2 plants produced per half a callus could have been due to development only from meristematric tissue and production of three or more plants per callus half (6 plantlets per callus) was thought to represent regeneration via the tissue culture process Regeneration potential was assessed after 3 weeks on MSR medium following the initial 3-week period of embryogenic callus culture and again after four subcultures (approxımately 16 weeks) on maintenance medium

\section{Statistical analysis}

Analysis of variance, using the size of the sample as a covanate, and the Waller-Duncan K-ratio $t$-test (Waller and Duncan 1969) were used to determine significant differences in regeneration potential between the 48 genotypes tested and the three initration media used

\section{Results}

With the exception of the line 'Gamtoos' (RWA), all bread wheats produced callus from immature embryos on at least one of the media. The first observed stage in the production of callus tissue was enlargement of the scutellar surface, which took place approximately 1 week after culture initiation, followed by the production of embryogenic callus after 2-3 weeks (Fig. 1). On N6 medium supplemented with dicamba (E1), embryos tended to form friable, white embryogenic calli, although sometimes more watery, less embryogenic calli were observed with some genotypes. E3 and E5 media produced calli very similar to each other; either paleyellow or yellow nodular embryogenic calli were observed. Not all of the calli produced were embryogenic, which accounts for the differences observed between the proportion of embryos producing calli and the proportion of calli producing regenerated plants (as observed with the genotype Seri M82) (Table 1). With some genotypes, the callus tissue either produced roots prematurely or became necrotic; this most frequently occurred on medium E5. In terms of the number of embryos forming callus, there were no significant differences between the three media across all genotypes $(P<0.001)$.

The embryogenic calli were transferred to the regeneration medium (MSR) where green parts appeared on a proportion of the calli after 4-7 days (Fig. 2), which developed into plantlets after approximately 3 weeks (Fig. 3).

The composition of the callus initiation medium appeared to be an important factor for subsequent plantlet regeneration on MSR medium. Taking the means of the regeneration potential for each genotype across all initiation media and for each media across all genotypes we found that there were statistically significant differences between regeneration percentages for both genotypes and media (both at the $1 \%$ level). The covariate analysis (data not shown) indicated that sample size (the number of embryos plated on each medium for each genotype) accounted for a sizeable portion of total variability with regards to percentage regeneration and was statistically significant (at the 5\% level).

Percentage regeneration varied widely with respect to both genotype and initiation medium with values ranging from $2 \%$ to $94 \%$ (Table 1) and number of plantlets produced per embryo ranging from 6 to 42 . Sixteen genotypes gave a minimum of $50 \%$ regeneration on at least one medium. A value of $50 \%$ for regeneration potential was chosen as a minimum since genotypes with values less than this are likely to produce low numbers of plants after transformation. 'Angostura' was the only genotype producing more than $50 \%$ regeneration on medium E1. Three genotypes showed more than $50 \%$ regeneration on medium E3 and 13 on E5 medium. Only 'Attila' and 'Luan' showed greater than $50 \%$ regeneration on two media(E3 and E5) with 'Luan' giving the highest regeneration potential $(94 \%$ on medium E5) of all the genotypes tested. The genotypes with the highest regeneration efficiencies (producing at least 20 plants per embryo) were 'Nanjing 780', 'Luan', 'Tia.2', 'Picus', 'Tinamou', 'Milan' and 'Catbird'. For each medium there were genotypes that did not produce embryogenic calli (or only formed calli producing fewer than 6 plantlets per embryo). For medium E1, 17 genotypes from 47 (36\%) showed no regeneration; for $\mathrm{E} 3,11$ from $47(23 \%)$ and for E5, 7 from $46(15 \%)$.

Table 1 shows the mean regeneration potentials for all 48 genotypes across the three media (taking into account sample size). 'Luan', 'Turaco', 'Milan' and 'Attila' were the best genotypes, with a mean regeneration potential exceeding $50 \%$ across the three media tested, while 'Angostura', 'Pavon', 'Tia.2' and 'Kauz' (X3) showed between $40-50 \%$ regeneration. Other genotypes, for example 'Tinamou', had a low mean regeneration potential $(20.7 \%)$ although on one of the media, in this case E5, the percentage regeneration was much higher $(86 \%)$ (Table 1). Similar results were observed for 'Cettia', 'Don Ernesto', 'Pastor, Munia' (X2), 'Catbird' and 'Bobwhite' where mean regeneration potentials were fairly low, but regeneration on one of the media was high. In contrast, the ninth highest performing variety was 'Munia' (X1), which responded similarly on all media but gave regeneration potentials of less than $50 \%$ on each medium. For the purpose of choosing genotypes and media for future transformation work it is desirable to select a genotype that gives high plant regeneration even if it does so on only one medium.

The Waller-Duncan test was also used to compare mean regeneration potentials on the three initiation media across all genotypes. For E5 medium, the mean 

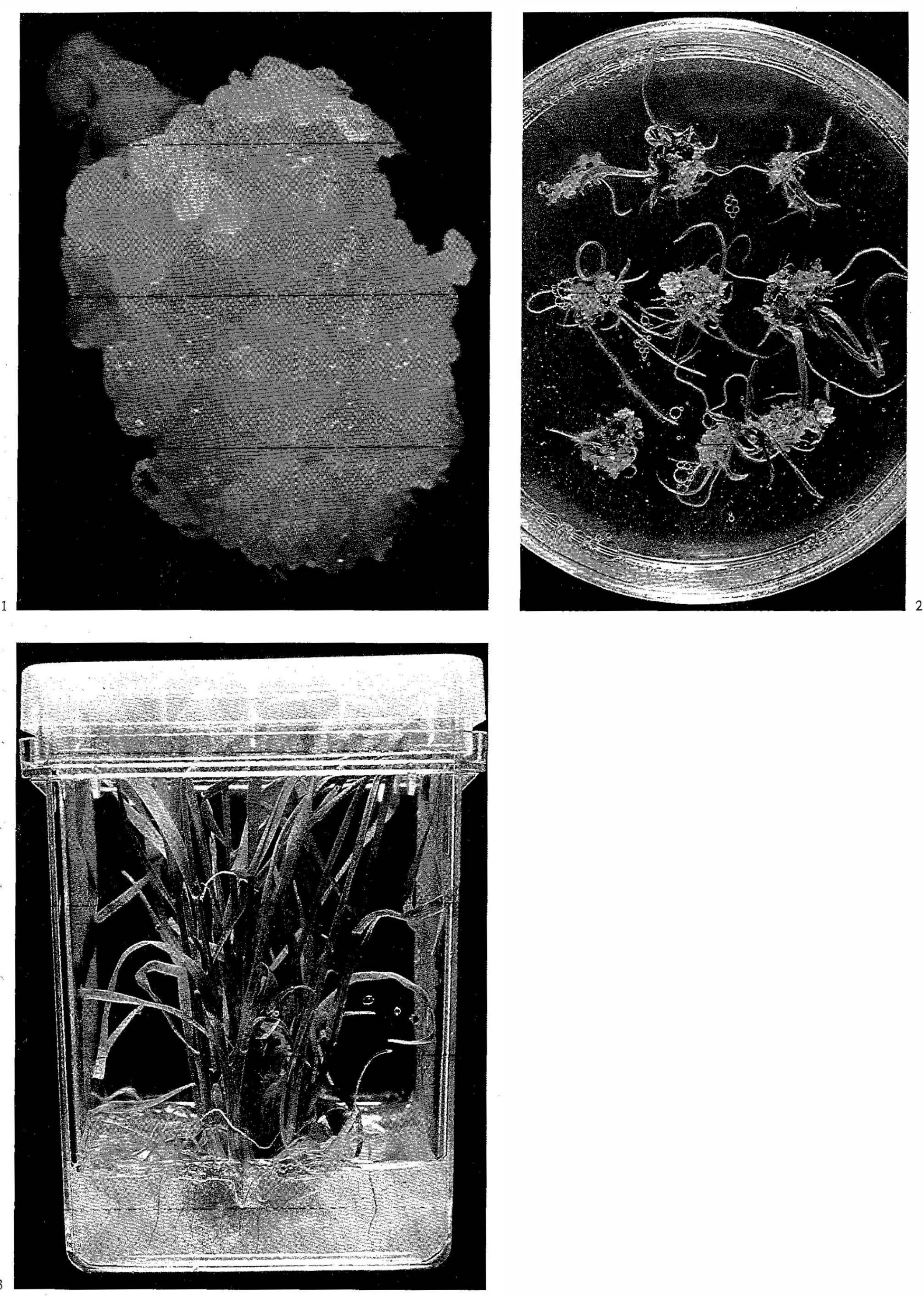
Fig. 1 Embyogenic callus formation from an immature embryo of 'Attila' on E3 medium Fig. 2 Embryogenic calli from immature embryos of 'Attila' possessing regeneration potential on MSR medium Fig. 3 Regenerated plantlets from 'Attila'

regeneration potential following callus initiation was $32.5 \%$, which was significantly higher than that for E3 $(15.4 \%)$ and E1 $(12.4 \%)$ (minimum significant difference $=6.3 \%$ ). Therefore, across all genotypes, medium E5 produced the highest proportion of embryogenic calli able to give rise to whole plants. However, after four subcultures over a 16-week period, only 7 lines possessed the ability to regenerate plantlets (Table 2), and most levels were substantially reduced. 'Filin', maintained on medium E3, was the genotype least affected by subculturing, which caused only a $10 \%$ reduction in regeneration potentials compared with that of 'Tinamou', whose regeneration potential was reduced by $96 \%$ after four subcultures. E3 medium was significantly better than E5 for sustained maintenance of regeneration potential. Regeneration on MSR medium, after initiation and 16 weeks of subculturing on E1, failed to produce plantlets in any of genotypes.

\section{Discussion}

Previous work by Bohorova et al. (1995) showed that media E1, E3 and E5 were able to produce embryogenic calli in 6 elite bread wheat varieties. In the current study, in which 48 elite bread wheats were evaluated, the findings of Bohorova et al. (1995) were confirmed, with each medium producing embryogenic callus for most lines. Although media E1, E3 and E5 responded equally well as initiation media for the production of calli, the proportion of this calli which was embryogenic and gave rise to regenerated plantlets varied with each medium. The calli produced on E1 medium were often non-compact and watery with few, if any, embryonic structures on the surface. E1 medium is basically N6 medium (Chu et al. 1975) supplemented - with dicamba. Some workers have found dicamba to be of value in the induction of embryogenesis in wheat (Maddock et al. 1983; Hunsinger and Schauz 1987). However, in our study, E1 medium seemed to be the least likely of the three to induce and maintain embryogenesis.

Both E3 and E5 media are based on MS medium (Murashige and Skoog 1962) and are supplemented with 2,4-D, a commonly used growth regulator in wheat tissue culture (O'Hara and Street 1978; Ahloowalia 1982; Carman et al. 1988; Elena and Ginzo 1988). The two media differ in several ways, including the type of supplementary amino acids. In addition, E5 contains kinetin and $\mathrm{GA}_{3}$, which $\mathrm{E} 3$ lacks. Though $\mathrm{E} 5$ medium was the best medium for induction of embryogenesis, E3 appeared to contain essential components that supported the maintenance of embryogenesis for 16 weeks (at least for 6 genotypes). Somatic embryogenesis is a complex morphogenic process, and its occurrence in tissue culture is due to a combination of several factors. Because the three initiation media used in this study are significantly different from each other in various respects it is not possible to attribute successful embryogenesis to any particular media component. In addition, at the stage of callus initiation from immature embryos, the most important factor regulating the percentage callus production seems to be the genotype rather than the media. Subsequently, in addition to the genotype, the callus initiation medium was also shown to greatly affect the ability of the embryogenic calli to regenerate plantlets (both initially and after four sub-cultures).

The fact that on the same medium some genotypes produced embryogenic calli and regenerated plants while others were completely incapable of regeneration suggests that there are genetic components controlling this trait. Several researchers have attempted to discover genes or regions within the wheat genome responsible for favourable tissue culture responses such as high plant regeneration potential (Galiba et al. 1986; Mathias and Fukui 1986; Felsenburg et al. 1987; Higgins and Mathias 1987; Kaleikau et al. 1989a, b; Langridge et al. 1991; Ben Amer et al. 1992). Chromosomes 7B, 7D and 1D (Galiba et al. 1986), 1RS (Langridge et al. 1991), 1BS, 2BS, 6BL (Felsenburg et al. 1987), 4BL (Mathias and Fukui 1986; Higgins and Mathias 1987) and 2DL, 2AL, 2BS and 2BL (Kaleikau et al. 1989a, b; Ben Amer et al. 1992) have all been identified as possessing regions responsible for these desirable tissue culture response characteristics. Mathias and Atkinson (1988) suggested that allelic variation in wheat at the Rht/Gai gene (reduced height/gibberellic acid insensitivity) may
Table 2 Elite genotypes possessing regeneration potential on MSR medium after four subcultures over a 16-week period

$\mathrm{X}$ indicates that the genotype was purified by controlled selfing

\begin{tabular}{lllc}
\hline Genotype & Callus initiation medium & $\begin{array}{l}\text { Plant regeneration(\%) } \\
\text { after 3 weeks }\end{array}$ & $\begin{array}{l}\text { Plant regeneration(\%) } \\
\text { after 16 weeks }\end{array}$ \\
\hline Tinamou (X) & E5 & 86 & 3 \\
Luan (X2) & E3 & 63 & 4 \\
Attila (X1) & E3 & 58 & 17 \\
Milan (X2) & E3 & 33 & 3 \\
Angostura (X3) & E3 & 21 & 2 \\
Filin(X) & E3 & 19 & 17 \\
Chuan Mai 21 (X) & E3 & 11 & 5 \\
\hline
\end{tabular}


effect callus growth, somatic embryogenesis and plant regeneration via an effect on hormonal metabolism. In addition, Ben Amer et al. (1992) showed that the semi-dwarfism allele Rht8 has a minor effect on wheat callus growth and regeneration ability and the allele $p p d l$ (day length sensitive) has a major effect on the same tissue culture traits. It can be suggested that one or more of these genes are being expressed in the highly regenerable genotypes on at least one of the media. Of the genotypes that performed well in terms of regeneration ability and efficiency, 'Nanjing 7840', 'Luan' and 'Catbird' are of Chinese origin and 'Luan' and 'Tia.2' contain an alien grass in their pedigrees. These factors may be contributing to high regeneration potentials. It is also possible that the $1 \mathrm{BL} / 1 \mathrm{RS}$ translocation could be partially responsible for such desirable tissue culture performance. Further work will be conducted at CIMMYT in an attempt to find the chromosomal regions responsible for high regeneration ability as this could aid in the future selection of genotypes for transformation. It is also possible that certain media components may regulate the expression of some of these genes as exemplified by 'Cettia' where regeneration potentials were significantly higher on one medium than on the other two. In contrast, this is unlikely with other genotypes, for example 'Munia' (X1), where regeneration potentials were not statistically different on the three different media used. In such cases the genotype, rather than the media, is the major factor influencing the regeneration potential of embryogenic calli. Wheat cultivars are known to differ in levels of cytokinins and auxins at seed maturation (Gale 1979; Mounla 1979). The better response of some lines, such as 'Luan', may therefore be due to the endogenous phytohormonal content and its regulatory influence.

The aim of this work was to identify bread wheat genotypes with the greatest potential for regeneration and select the best lines for transformation experiments. It is likely that after transformation, using the biolistic approach, levels of regeneration will be reduced due to disruption of cellular processes. After bombardment, 9 weeks may be required for three cycles of selection to identify transformed from non-transformed material. Hence, the selected genotypes should not only have high regeneration potential, but the latter should be maintainable for at least 9 weeks. Our study has shown that only 7 lines retained their ability to regenerate plantlets after 16 weeks of subculturing.

Two genotypes, 'Attila' and 'Luan', have been selected for initial transformation experiments because they possess high regeneration potentials and also because of their importance to CIMMYT wheat breeding programmes. 'Attila' was one of the best performing lines in tissue culture, and initial transformation experiments have shown that its plantlets can be regenerated after the three cycles of selection following particle bombardment using E3 as the callus initiation medium.
Acknowledgements The authors would like to thank B. Luna, L Huerta and M. Ramos for their excellent technical assistance and Wolfgang Pfeiffer and Mujeeb Kazi for their useful comments on this manuscirpt They acknowledge the Overseas Development Administration (ODA), UK, for funding S Fennell on the APOS scheme

\section{References}

Ahloowalia BS (1982) Plant regeneration from callus culture in wheat Crop Scr 22 405-410

Ben Amer IM, Worland AJ, Schlegel R (1992) In vitro culture variation of wheat and rye caused by genes affecting plant growth habit in vivo Euphytica 61 233-240

Bohorova NE, van Ginkel M, Rajaram S, Hoisington DA (1995) Tissue culture response of CIMMYT elite bread wheat varieties and evaluation of regenerated plants. Cereal Res Comm (1n press)

Carman JG, Jefferson NE, Campbell WF (1988) Induction of embryogenic Tritıcum aestivum L. call I Quantification of genotype and culture medium effect Plant Cell Tissue Org Cult 12.83-95

Chu CC, Wang CC, Sun CS, Hsu C, Yın KC, B1 CV (1975) Establishment of an efficient medium for anther culture of rice through comparative experiments on the nitrogen source Sci Sinica $18 \cdot 659-668$

Elena EB, Ginzo HD (1988) Effect of auxin levels on shoot formation with different embryo tissues from a cultivar and a commercial hybrid of wheat (Triticum aestivum L ). J Plant Physiol 132 600-603

Felsenburg T, Feldman M, Galun E (1987) Aneuplord and alloplasmic lines as tools for the study of nuclear and cytoplasmic control of culture ability and regeneration of scutellar calli from common wheat Theor Appl Genet 74 802-810

Gale MD (1979) Genetıc variation for hormonal activity and yield In Spiertz JHJ, Kramer Th (eds) Crop physiology and cereal breeding. Centre for Agric Pub and Documentation, Wagenıngen, The Netherlands, pp 29-34

Galiba G, Kovacs G, Sutka J (1986) Substitution analysıs of plant regeneration from callus culture in wheat Plant Breed 97 261-263

Gosh-Wackerle G, Avivı L, Galun E (1979) Induction, culture and differentiation of callus from immature rachises, seeds and embryos of Tritıclum Z Pflanzenphysiol 91 267-278

He DG, Yang YM, Scott KJ (1989) The effect of macroelements in the induction of embryogenic callus from immature embryos of wheat (Tritıcum aestivum L.) Plant Sc1 64 251-258

Higgins P, Mathras RJ (1987) The effect of the 4B chromosomes of hexaploid wheat on the growth and regeneration of callus cultures. Theor Appl Genet 74 439-444

Hunsinger H, Schauz K (1987) The influence of dicamba on somatic embryogenesis and frequency of plant regeneration from cultured immature embryos of wheat (Tritıcum aestivum L). Plant Breed 98.119-123

Kaleilau EK, Sears RG, G11l BS (1989a) Monosomic analysis of tissue culture response in wheat (Triticum aestivum L) Theor Appl Genet 78 783-787

Langridge P, Lazzerı P, Lorz H (1991) A segment of rye chromosome 1 enhances growth and embryogenesis of call derived from immature embryos of wheat Plant Cell Rep 10 148-151

Lazar MD, Collins GB, Vian WE (1983) Genetic and environmental effects on the growth and differentiation of wheat somatic cultures. J Hered 74·353-357

Maddock SE, Lancaster VA, Risıott R, Franklın J (1983) Plant regeneration from cultured immature embryos and inflorescences of 25 cultivars of wheat (Triticum aestivum). J Exp Bot 34 -915-926

Mathias RJ, Atkınson E (1988) In vitro expression of genes affecting whole plant phenotype - the effect of Rht/Gal alleles on the callus culture response of wheat (Triticum aestivum L em Thell) Theor Appl Genet 75 474-479

Mathias RJ, Fukuı K (1986) The effect of specific chromosome and cytoplasm substitutions on the tissue culture response of wheat (Tritıcum aestivum) callus Theor Appl Genet 71.797-800

Mathias RJ, Simpson ES (1986) The interaction of genotype and culture medium on the tissue culture responses of wheat (Triticum aestivum L) callus Plant Cell Tissue Org Cult 7.31-37 
Mounla MAKh (1979) Phytohormones and grain growth in cereals. In: Spiertz JHJ, Kramer Th (eds) Crop physiology and cereal breeding. Centre for Agric Pub and Documentation, Wageningen, The Netherlands, pp 20-28

Murashige T, Skoog F (1962) A revised medium for rapid growth and bioassays with tobacco tissue cultures. Plant Physiol 15:473-497

O'Hara JF, Street HE (1978) Wheat callus culture: the initiation, growth and organogenesis of callus derived from various explant sources. Ann Bot 42:1029-1038

Ozias-Akins P, Vasil IK (1982) Plant regeneration from cultured immature embryos and inflorescences of Triticum aestivum $\mathrm{L}$. (wheat): evidence for somatic embryogenesis. Protoplasma 110:95-105
Ozias-Akins P, Vasil IK (1983) Improved efficiency and normalization of somatic embryogenesis in Triticum aestivum (wheat). Protoplasma 116:40-44

Sears RG, Deckard EL (1982) Tissue culture variability in wheat: callus induction and plant regeneration. Crop Sci 22: $546-550$

Shimada T (1978) Plant regeneration from the callus induced from wheat embryos. Jpn J Genet 53:371-374

Shimada T, Yamada Y (1979) Wheat plants regenerated from embryo cell cultures. Jpn J Genet 54:379-385

Waller RA, Duncan DB (1969) A Bayes rule for the symmetric multiple comparison problem. J Am Stat Assoc 64:1484-1503 